\title{
Prevalence of microcephaly in Europe: population based study
}

\author{
Joan K Morris, ${ }^{1}$ Judith Rankin, ${ }^{2}$ Ester Garne, ${ }^{3}$ Maria Loane, ${ }^{4}$ Ruth Greenlees, ${ }^{4}$ Marie-Claude Addor, ${ }^{5}$ \\ Larraitz Arriola, ${ }^{6}$ Ingeborg Barisic, ${ }^{7}$ Jorieke E H Bergman, ${ }^{8}$ Melinda Csaky-Szunyogh, ${ }^{9}$ Carlos Dias, ${ }^{10}$ \\ Elizabeth S Draper, ${ }^{11}$ Miriam Gatt, ${ }^{12}$ Babak Khoshnood, ${ }^{13}$ Kari Klungsoyr, ${ }^{14}$ Jennifer J Kurinczuk, ${ }^{15}$ \\ Catherine Lynch, ${ }^{16}$ Robert McDonnell, ${ }^{17}$ Vera Nelen, ${ }^{18}$ Amanda J Neville, ${ }^{19}$ Mary T O'Mahony, ${ }^{20}$ \\ Anna Pierini, ${ }^{21}$ Hanitra Randrianaivo, ${ }^{22}$ Anke Rissmann, ${ }^{23}$ David Tucker, ${ }^{24}$ Christine Verellen-Dumoulin, ${ }^{25}$ \\ Hermien E K de Walle, ${ }^{8}$ Diana Wellesley, ${ }^{26}$ Awi Wiesel, ${ }^{27}$ Helen Dolk ${ }^{4}$
}

For numbered affiliations see end of article.

Correspondence to: J Morris j.k.morris@qmul.ac.uk

Cite this as: $B M J$ 2016;354:i4721 http://dx.doi.org/10.1136/bmj.i4721

Accepted: 30 August 2016

\section{ABSTRACT}

\section{OBJECTIVES}

To provide contemporary estimates of the prevalence of microcephaly in Europe, determine if the diagnosis of microcephaly is consistent across Europe, and evaluate whether changes in prevalence would be detected using the current European surveillance performed by EUROCAT (the European Surveillance of Congenital Anomalies).

\section{DESIGN}

Questionnaire and population based observational study.

SETTING

24 EUROCAT registries covering 570000 births annually in 15 countries.

\section{PARTICIPANTS}

Cases of microcephaly not associated with a genetic condition among live births, fetal deaths from 20 weeks' gestation, and terminations of pregnancy for fetal anomaly at any gestation.

\section{MAIN OUTCOME MEASURES}

Prevalence of microcephaly (1 Jan 2003-31 Dec 2012) analysed with random effects Poisson regression models to account for heterogeneity across registries. RESULTS

16 registries responded to the questionnaire, of which $44 \%$ (7/16) used the EUROCAT definition of microcephaly (a reduction in the size of the brain with a skull circumference more than 3 SD below the mean for sex, age, and ethnic origin), 19\% (3/16) used a 2 SD

\section{WHAT IS ALREADY KNOWN ON THIS TOPIC}

Maternal infection with Zika virus during the first trimester of pregnancy increases the risk of microcephaly in the baby

In South America clinicians noticed a dramatic increase in the prevalence of microcephaly, which was confirmed by surveillance

European surveillance of congenital anomalies is performed by EUROCAT (the European Surveillance of Congenital Anomalies; www.eurocat-network.eu/)

\section{WHAT THIS STUDY ADDS}

The reported prevalence of microcephaly across Europe varies considerably because of the different diagnostic criteria applied and varying levels of ascertainment

EUROCAT could detect increases in the prevalence of microcephaly due to the Zika virus of a similar magnitude to those observed in Brazil

Because Aedes mosquitoes are not indigenous in most of Europe, associated increases in the prevalence of microcephaly would probably be smaller and unlikely to be detected cut off, 31\% (5/16) were reliant on the criteria used by individual clinicians, and one changed criteria between 2003 and 2012. Prevalence of microcephaly in Europe was 1.53 (95\% confidence interval 1.16 to 1.96 ) per 10000 births, with registries varying from $0.4(0.2$ to 0.7 ) to 4.3 (3.6 to 5.0$)$ per $10000\left(\chi^{2}=338, \mathrm{df}=23\right.$, $\left.\mathrm{I}^{2}=93 \%\right)$. Registries with a 3 SD cut off reported a prevalence of 1.74 per 10000 (0.86 to 2.93) compared with those with the less stringent 2 SD cut off of 1.21 per 10000 ( 0.21 to 2.93). The prevalence of microcephaly would need to increase in one year by over $35 \%$ in Europe or by over $300 \%$ in a single registry to reach statistical significance $(P<0.01)$.

CONCLUSIONS

EUROCAT could detect increases in the prevalence of microcephaly from the Zika virus of a similar magnitude to those observed in Brazil. Because of the rarity of microcephaly and discrepant diagnostic criteria, however, the smaller increases expected in Europe would probably not be detected. Clear diagnostic criteria for microcephaly must be adopted across Europe.

\section{Introduction}

Microcephaly is a congenital anomaly where a baby's head is smaller compared with other babies of the same sex, age, and ethnicity. The definition of "smaller" varies from a head circumference more than 2SD below the mean to more than 3 SD below the mean. The more extreme the definition of "smaller" the greater the proportion of babies diagnosed with microcephaly who will have smaller underdeveloped brains and who are consequently at risk of developmental delay, intellectual disability, and physical disabilities such as hearing and vision impairment. ${ }^{1}$ In a cohort of 680 children with microcephaly the aetiology was genetic in $31 \%$, perinatal brain injuries in $27 \%$ (including maternal exposure to teratogens in 4\%), postnatal brain injuries in $2 \%$, and unknown in $41 \% .^{2}$

In late 2015, there were reports of a dramatic increase in the prevalence of microcephaly in Brazil, coinciding with an outbreak of the Zika virus several months earlier. ${ }^{3}$ There is now sufficient evidence to confirm that infection with the Zika virus during the first trimester of pregnancy increases the risk of microcephaly in the baby. ${ }^{45}$ The emerging microcephaly epidemic across South America has highlighted the necessity of accurate congenital anomaly surveillance.

We carried out a population based study to provide contemporary estimates of the prevalence of 
microcephaly in Europe, determine if the diagnosis of microcephaly is consistent across Europe, and evaluate whether changes in prevalence would be detected with the current European surveillance performed by EUROCAT (the European Surveillance of Congenital Anomalies; www.eurocat-network.eu/).

\section{Methods}

EUROCAT is a European network of almost all population based registries of congenital anomaly in Europe and currently provides the most complete information on congenital anomalies occurring in the area. EUROCAT was established in 1979, and there are currently 43 registries in 23 countries covering more than $29 \%$ of European births (1.7 million) each year. The European Union has provided funding for a central registry to coordinate the network, and the member registries are funded locally by national or regional governments, research, or other bodies. All EUROCAT registries have a defined geographical coverage (a map for registries included in EUROCAT can be found at www.eurocat-network.eu/content/EUROCAT-Population-Table-I-Year2012.pdf); in some countries all births are covered by a registry (such as in Hungary, Malta, Norway, Poland, and Sweden) and in some countries less than $10 \%$ are covered by a registry (such as in Germany, the Netherlands, and Ukraine).

All EUROCAT registries use multiple sources of information to ascertain cases among all live births, late fetal deaths ( $>20$ weeks' gestation), and terminations of pregnancy for fetal anomaly at any gestation. ${ }^{6}$ Data sources, depending on registry, include maternity, neonatal, and paediatric records; fetal medicine, cytogenetic, pathology, and medical genetics records; specialist services including paediatric cardiology; and hospital discharge and child health records. The EUROCAT central database is hosted by the European Commission Joint Research Centre in Ispra, Italy, since 2015. Registries either submit individual anonymised records of cases of congenital anomalies (full members) or submit the same data in aggregate form (associate members). All cases are coded with ICD-9 or ICD-10 (international classification of diseases, ninth or 10th versions) with 1-digit British Paediatric Association (BPA) extension. In each case there can be one syndrome and up to eight malformation codes. All coding is standardised by using the EUROCAT guide (version 1.4) with isolated minor anomalies, such as skin tags, being excluded. ${ }^{7}$

A set of 30 data quality indicators is used to assess five key elements of data quality: completeness of case ascertainment, accuracy of diagnosis, completeness of information on EUROCAT variables, timeliness of data transmission, and availability of population denominator information. ${ }^{8}$ Surveillance and research are performed with data only from registries with sufficiently high data quality. For inclusion in the annual monitoring of trends, registries must not be more than a year behind in data transmission and have provided data for at least nine of the previous 10 years. ${ }^{9}$ Twenty five registries satisfied these criteria for 1 January 2003 to 31 December 2012. ${ }^{10}$
In EUROCAT's annual monitoring of trends for congenital anomalies excluding genetic conditions, all cases with a chromosomal anomaly, genetic syndrome, microdeletion, or skeletal dysplasia are excluded for two reasons. Firstly, registries differ in their reporting of associated anomalies in cases with a genetic condition, and, secondly, these genetic conditions are aetiologically different from other anomalies. For example, over $10 \%$ of infants with Patau syndrome have microcephaly ${ }^{11}$ and the risk of a pregnancy with Patau syndrome increases with maternal age. Therefore, if mean maternal age increases in a population, there would be more cases of Patau syndrome and hence also more cases of microcephaly. This increase in microcephaly could mask other important trends from changes in the exposure to teratogens. Known genetic conditions are well recorded as most registries receive information directly from cytogenetic laboratories, as indicated by a specific data quality indicator assessing ascertainment of Down's syndrome. In April 2014, the EUROCAT central registry held at Ulster University extracted aggregate data on all cases of microcephaly excluding genetic conditions from 1 Jan 1980 to 31 Dec 2012.

The EUROCAT definition of microcephaly is "a reduction in the size of the brain with a skull circumference more than 3 SD below the mean for sex, age and ethnic origin." Many registries, however, receive the diagnosis of microcephaly from a clinician and might not be able to ensure that the EUROCAT definition is used. To find out whether this was the case, we sent a questionnaire to all EUROCAT registries with the following questions:

- Do you have a strict definition of microcephaly?

- Do you use the EUROCAT definition?

- Do you use growth charts for defining microcephaly?

- Do you report the cases that the clinicians report to you or do you assess the diagnosis within your registry?

We fitted a Poisson random effects model to estimate the European prevalence of microcephaly from 2003 to 2012 and examined the degree of heterogeneity using the $\mathrm{I}^{2}$ test statistic. ${ }^{910}$ We used a Poisson model as these models are used to predict the number of times a rare event (in this case microcephaly) will occur when many general events occur (in this case all pregnancies). A random effects model assumes that the true prevalence of microcephaly in each registry will vary. Poisson regression models were fitted for the number of microcephaly cases diagnosed each year with the total number of births in the population each year as the exposure variable to examine linear trends in the years from 2003 to 2012 for each registry separately. Multilevel Poisson regression models were also fitted with the data from 1980 to 2012, with data from each two yearly interval combined and entered as a categorical variable and each registry as a stratum to estimate a registry adjusted two yearly prevalence of microcephaly. We chose two years to reduce the random fluctuations present in the data. All analyses were performed with Stata software version 12. 


\section{Patient involvement}

As this study is part of EUROCAT's routine surveillance of congenital anomalies no patients were involved in setting the research question or the outcome measures, nor were they involved in developing plans for implementation of the study. No patients were asked to advise on the interpretation or writing up of results. There are no plans to disseminate the results of the research to study participants. However, the results will be available on the EUROCAT website.

\section{Results}

Sixteen of the 25 participating registries (64\%) replied to the EUROCAT microcephaly questionnaire. In 2006 one registry changed their diagnostic criteria for microcephaly from below the 10th centile to below the 3rd centile so it was therefore excluded from the data analysis. Seven (44\%) registers used the $3 \mathrm{SD}$ cut off recommended by EUROCAT, three (19\%) used a 2 SD cut off, and the remaining five (31\%) registers relied on the criteria used by individual clinicians. Most registries used country specific growth charts, with one registry using the WHO 2006 Child Growth Standard. ${ }^{12}$

Table 1 shows the considerable variations in birth population surveyed by the 24 registries, with the largest registry covering almost 100000 births a year and the smallest only 3500 . Microcephaly is a rare congenital anomaly and hence only two registries (8\%) recorded an average of more than 10 cases a year, and 15 registries (63\%) had at least one year from 2003 to 2012 during which they did not record a single case. In total, there were 570000 births resulting in 100 cases of microcephaly a year. Figure 1 shows the changes in the biennial prevalence (adjusted for registry) from 1980 to 2012. The small number of cases per year means that large changes in prevalence will occur due to chance, such as the $37 \%$ increase in European prevalence from 1992 to 1994

The estimated prevalence of microcephaly in Europe from 2003 to 2012 was 1.53 (95\% confidence interval 1.16 to 1.96) per 10000 births (fig 2). There was considerable heterogeneity between registries $\left(\chi^{2}=338, \mathrm{df}=23\right.$, $\left.\mathrm{I}^{2}=93 \%\right)$. There was no indication that registries that used more stringent diagnostic criteria had a lower prevalence than those with less stringent criteria: seven registries that used the 3 SD cut off reported a prevalence of 1.74 per 10000 (95\% confidence interval 0.86 to 2.93), three registries that used a 2 SD cut off reported a prevalence of 1.21 per 10000 (0.21 to 2.93), and five registries that relied on the criteria used by individual clinicians reported a prevalence of 1.81 per 10000 (0.29 to 4.57).

For the 10 years from 2003 to 2012, there was an average annual decrease in the prevalence of microcephaly of $2 \%$ (95\% confidence interval $-4 \%$ to $0 \%$ ) a year (table 1). There was considerable heterogeneity between registries for this trend in prevalence $\left(\chi^{2}=79.29, \mathrm{df}=23\right.$, $\left.\mathrm{I}^{2}=71 \%\right){ }^{10}$

\section{Discussion}

The prevalence of microcephaly across Europe varies considerably, probably due to a combination of three different factors: the diagnostic criteria and how they are applied; the different levels of ascertainment

\begin{tabular}{|c|c|c|c|c|c|c|c|c|}
\hline Registry & 1st year & $\begin{array}{l}\text { Final } \\
\text { year }\end{array}$ & $\begin{array}{l}\text { No of } \\
\text { years } \\
\text { of data }\end{array}$ & $\begin{array}{l}\text { Average No } \\
\text { of cases/year }\end{array}$ & $\begin{array}{l}\text { Average No of } \\
\text { births/year }\end{array}$ & $\begin{array}{l}\text { No of years } \\
\text { with no cases } \\
2003-12\end{array}$ & $\begin{array}{l}\text { No of cases/ } 10000 \\
\text { births } 2003-12(95 \% \mathrm{Cl})\end{array}$ & $\begin{array}{l}\text { Annual \% change in } \\
\text { prevalence } 2003-12 \\
(95 \% \mathrm{Cl})\end{array}$ \\
\hline Hungary & 1998 & 2011 & 14 & 15.3 & 96297 & 0 & $1.8(1.6$ to 2.1$)$ & $2(-4$ to 8$)$ \\
\hline UK, East Midlands and South Yorkshire & 1998 & 2012 & 15 & 8.5 & 66577 & 0 & $1.0(0.8$ to 1.3$)$ & $-6(-13$ to 2$)$ \\
\hline Norway & 1999 & 2012 & 14 & 2.7 & 59753 & 1 & $0.5(0.3$ to 0.7$)$ & $-2(-14$ to 12$)$ \\
\hline UK, Wales & 1998 & 2012 & 15 & 15.8 & 33448 & 0 & 4.3 (3.6 to 5.0$)$ & $-11(-16$ to -6$)$ \\
\hline France, Paris & 1981 & 2012 & 32 & 8.0 & 33044 & 0 & $2.9(2.3$ to 3.6$)$ & $8(0$ to 17$)$ \\
\hline UK, Northern England & 2000 & 2012 & 13 & 4.5 & 32056 & 1 & 1.3 (0.9 to 1.7$)$ & $-17(-26$ to -7$)$ \\
\hline Italy, Emilia Romagna & 1981 & 2012 & 32 & 3.4 & 28484 & 1 & 1.2 (0.9 to 1.6$)$ & $13(1$ to 26$)$ \\
\hline UK, Wessex & 1994 & 2012 & 19 & 2.3 & 27599 & 0 & 0.8 (0.6 to 1.2$)$ & $-11(-23$ to 3$)$ \\
\hline Ireland, Dublin & 1980 & 2012 & 33 & 6.3 & 22521 & 0 & 2.2 (1.7 to 2.9$)$ & $-18(-26$ to -10$)$ \\
\hline Italy, Tuscany & 1980 & 2012 & 33 & 1.8 & 20809 & 0 & 0.7 (0.4 to 1.0$)$ & $-9(-23$ to 6$)$ \\
\hline Spain, Basque Country & 1990 & 2011 & 22 & 3.6 & 18155 & 0 & 2.9 (2.2 to 3.8) & 11 (0 to 23$)$ \\
\hline Netherlands, North & 1981 & 2012 & 32 & 3.8 & 16581 & 1 & $1.7(1.2$ to 2.4$)$ & 16 (1 to 32$)$ \\
\hline Belgium, Antwerp & 1990 & 2012 & 23 & 4.0 & 15778 & 1 & 2.3 (1.7 to 3.1$)$ & $-3(-13$ to 7$)$ \\
\hline Portugal, South & 1990 & 2011 & 22 & 1.8 & 15432 & 5 & 0.4 (0.2 to 0.8$)$ & $0(-17$ to 19$)$ \\
\hline UK, Thames Valley & 1991 & 2012 & 22 & 1.1 & 14679 & 1 & 0.9 (0.6 to 1.4$)$ & $-1(-8$ to 6$)$ \\
\hline France, Isle de Reunion & 2002 & 2012 & 11 & 4.6 & 14596 & 0 & $3.2(2.4$ to 4.3$)$ & 22 (9 to 36$)$ \\
\hline Belgium, Hainaut & 1980 & 2012 & 33 & 2.6 & 11465 & 1 & 1.5 (1.0 to 2.3$)$ & $-4(-13$ to 5$)$ \\
\hline Ireland, Cork and Kerry & 1996 & 2012 & 17 & 2.1 & 8907 & 5 & $0.9(0.5$ to 1.8$)$ & $-3(-15$ to 12$)$ \\
\hline Switzerland, Vaud & 1989 & 2012 & 24 & 1.5 & 7600 & 2 & 1.7 (1.0 to 2.9$)$ & $1(-12$ to 16$)$ \\
\hline Ireland, South East & 1997 & 2012 & 16 & 2.1 & 6796 & 3 & 2.3 (1.4 to 3.7$)$ & $-12(-26$ to 4$)$ \\
\hline Croatia, Zagreb & 1983 & 2012 & 30 & 1.7 & 6367 & 6 & $0.6(0.2$ to 1.5$)$ & $4(-9$ to 18$)$ \\
\hline Denmark, Odense & 1980 & 2012 & 33 & 1.0 & 5272 & 6 & $1.0(0.4$ to 2.3$)$ & $-7(-20$ to 9$)$ \\
\hline Malta & 1986 & 2011 & 26 & 1.2 & 4619 & 1 & $3.0(1.7$ to 5.4$)$ & $3(-9$ to 17$)$ \\
\hline Germany, Mainz & 1990 & 2011 & 22 & 0.4 & 3425 & 6 & 1.4 (0.5 to 3.6) & 1 (-15 to 21$)$ \\
\hline European estimate & - & - & - & 100.1 & 570260 & - & 1.53 (1.16 to 1.96$)$ & $-2(-4$ to 0$)$ \\
\hline
\end{tabular}




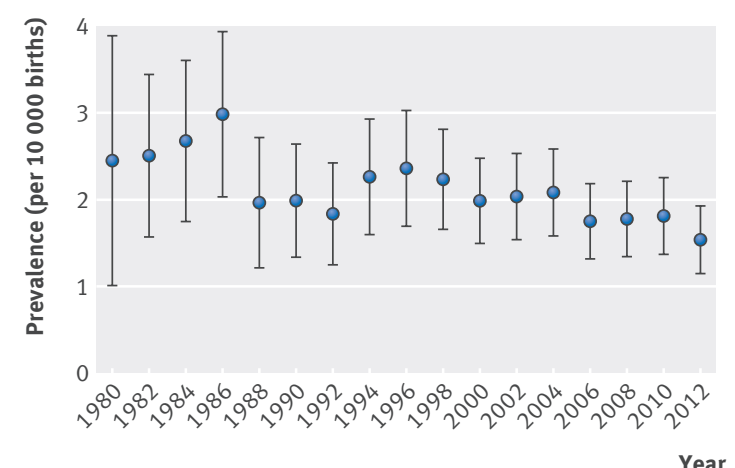

Fig 1 | European prevalence (per 10000 births) and 95\% confidence intervals of microcephaly excluding genetic conditions, 1980-2012
UK, Wales

France, Isle de Reunion

Malta

Spain, Basque Country

France, Paris

Ireland, South East

Belgium, Antwerp

Ireland, Dublin

Hungary

Switzerland, Vaud

Netherlands, North

Belgium, Hainaut

Germany, Mainz

UK, Northern England

Italy, Emilia Romagna

UK, East Midlands and South Yorkshire

Denmark, Odense

Ireland, Cork and Kerry

UK, Thames Valley

UK, Wessex

Italy, Tuscany

Croatia, Zagreb

Norway

Portugal, South

European prevalence
Prevalence $(95 \% \mathrm{Cl})$

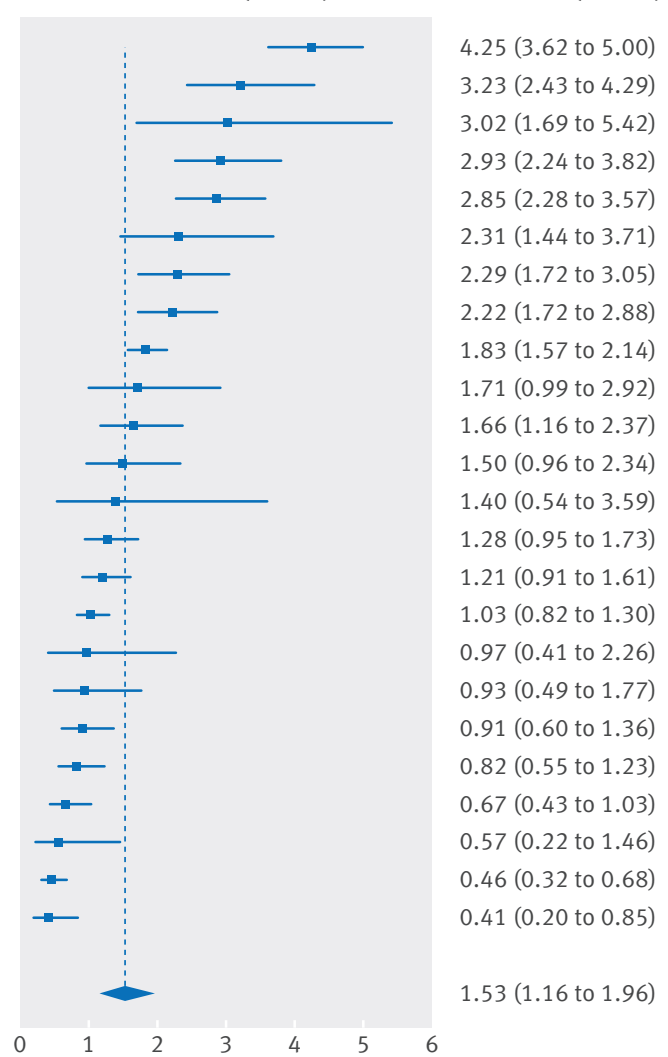

Fig 2 | Prevalence (per 10000 births) and 95\% confidence intervals of microcephaly excluding genetic conditions according to EUROCAT registry (2003-12) associated anomalies in cases with a genetic condition. ${ }^{11}$ Inflation of the observed prevalence of microcephaly in this study by $31 \%$ gives an estimated prevalence of microcephaly including genetic conditions of 2.0 per 10000 (95\% confidence interval 1.53 to 1.31). This compares with reported prevalences, including genetic conditions, of 1.98 per 10000 (1.48 to 2.27) by ECLAMC in Brazil (before the Zika virus epidemic), ${ }^{13}$ 2.3 per 10000 (1.82 to 2.78) in India, ${ }^{14}$ and 6.0 per 10000 (4.5 to 7.7) in the US. ${ }^{15}$

Around 100 cases of microcephaly occur each year (table 1). As the occurrence of cases has an approximate Poisson distribution, if the number of births does not change significantly there would have to be an increase of over 35\% of cases in a year for this to be identified as a significant increase at $\mathrm{P}<0.01$ (100 $v 135$ is $\mathrm{P}=0.009)$. The average number of cases per registry per year is four (table 1), and hence the equivalent increase in prevalence would be over $300 \%$ in a single registry to reach significance ( $4 v 13 ; \mathrm{P}=0.006)$. If multiple comparisons were adjusted for, such increases would need to be greater. EUROCAT annual statistical monitoring also uses scan statistic methods within registries, and this would also require an increase of over $300 \%$ to be likely to be detected. ${ }^{16}$

In Brazil, the increase in reporting of microcephaly by the Live Birth Information System (Sistema de Informações sobre Nascidos Vivos, SINASC) was about fourfold in the country as a whole, with the prevalence in the north east rising 10-fold, though these increases were partly influenced by improved ascertainment. ${ }^{1317}$ As calculated above, the EUROCAT surveillance system would have detected increases of this magnitude. Future increases in prevalence of microcephaly in Europe due to the Zika virus, however, would be expected to be considerably smaller than those that have occurred in South America because Aedes mosquitoes are not indigenous in Europe. Such changes in prevalence would therefore be unlikely to be detected through routine surveillance. Maternal exposure to the Zika virus, however, should be considered for any newly diagnosed microcephaly cases.

\section{Strengths and weaknesses}

The strength of this study is that the EUROCAT registries are population based and cover 600000 births annually in 15 countries. In addition, all cases are included, not just those in infants who are receiving treatment at specialist hospitals. A limitation of EUROCAT is that the definition of microcephaly is, for many registries, at the discretion of the patient's clinician. This means that standardising diagnostic criteria can be difficult. There are clear discrepancies in the application of the diagnostic guidelines as if head circumference had a Gaussian (normal) distribution we would expect the head circumference in $0.13 \%$ of babies to be more than 3 SD below the mean and in $2.3 \%$ to be more than $2 \mathrm{SD}$ below the mean (prevalences of around 13 per 10000 to 230 per 10000), which is inconsistent with the observed prevalences from Europe, Brazil, India, and the US. ${ }^{14} 1517$ In the case of microcephaly, collection of additional
EUROCAT a genetic condition was recorded in an additional $23 \%$ of microcephaly cases. This is lower than the $31 \%$ of cases with a genetic condition observed in a study on the aetiology of microcephaly in 680 children. ${ }^{2}$ This could be because some registries do not include all 
information such as the gestational age of the baby at birth, the age of the baby at the time of diagnosis of microcephaly, the head circumference of the child, and the ethnic group of the child would enable EUROCAT to more accurately determine discrepancies in diagnosis and also to ensure more consistent diagnostic criteria.

The recent (4 March 2016) WHO interim guidelines for diagnosing microcephaly are: "Neonates with a head circumference more than 2 standard deviations below the mean are considered to have microcephaly. Neonates with a head circumference more than 3 standard deviations below the mean should be considered to have severe microcephaly." 18 Implementation of this new definition will greatly increase the prevalence of microcephaly, with potentially an additional 2.2\% $(2.3 \%-0.1 \%)$ of babies having a diagnosis of microcephaly. This will result in a much greater proportion of babies labelled as microcephalic who will have no detectable neurological impairment. ${ }^{1}$ The feasibility of such a change requires further assessment. The application of the WHO definition has other limitations in Europe. The WHO has a set of tables with head circumference for term neonates ${ }^{12}$ and recommends the use of Intergrowth standards for preterm neonates. ${ }^{19}$ Studies from Norway, Belgium, and the UK, however, have found that the WHO tables are not accurate for the children in their cohorts ${ }^{2021}$; these children had larger heads, which would result in the underdiagnosis of microcephaly. Similarly, these tables might not be suitable for children from other ethnic groups that have smaller heads on average.

\section{Conclusions}

The emergence of the Zika virus and its association with microcephaly highlights the necessity for a more standardised application of agreed diagnostic criteria. It also emphasises the necessity of continued surveillance of all congenital anomalies within each country in Europe. Potential teratogens are often identified by alert clinicians (such as in the case of thalidomide). Congenital anomaly registries with accurate baseline data are then essential to evaluate the true severity of any new epidemic. For rare diseases, the pooling of standardised data across Europe by EUROCAT to obtain accurate baseline data is essential to detect and evaluate any future environmental teratogens in a timely manner.

\section{AUTHOR AFFILIATIONS}

Wolfson Institute of Preventive Medicine, Queen Mary University of London, London, UK

2Institute of Health and Society, Newcastle University, Newcastle upon Tyne, UK

${ }^{3}$ Paediatric Department, Hospital Lillebaelt, Kolding, Denmark

«University of Ulster, Newtownabbey, Co Antrim, Northern Ireland, UK

${ }^{5}$ Division of Medical Genetics, Lausanne, Switzerland

${ }^{6}$ Public Health Division of Gipuzkoa, Instituto BIO-Donostia, Basque Government, CIBER Epidemiologia y Salud Publica - CIBERESP, Spain

${ }^{7}$ Children's Hospital Zagreb, Medical School University of Zagreb, Zagreb, Croatia

${ }^{8}$ University of Groningen, University Medical Centre Groningen, Department of Genetics, Groningen, Netherlands
${ }^{9}$ National Public Health and Medical Officer Service, Hungarian Congenital Abnormality Registry, Budapest, Hungary

${ }^{10} \mathrm{Centro}$ de Estudos e registo de A C, Lisbon, Portugal

${ }^{11}$ University of Leicester, Leicester, UK

${ }^{12}$ Department of Health Information and Research, Guardamangia, Malta

13INSERM, Paris, France

${ }^{14}$ Department of Global Public Health and Primary Care, University of Bergen, and Medical Birth Registry of Norway, Norwegian Institute of Public Health, Bergen, Norway

${ }^{15}$ National Perinatal Epidemiology Unit, University of Oxford, Oxford, UK

${ }^{16}$ Health Service Executive, Kilkenny, Republic of Ireland

${ }^{17}$ Health Service Executive, Dublin, Republic of Ireland

${ }^{18}$ Provincial Institute for Hygiene, Antwerp, Belgium

${ }^{19}$ IMER Registry, Centre for Clinical and Epidemiological Research, University of Ferrara and Azienda Ospedaliero- Universitaria di Ferrara, Ferrara, Italy

${ }^{20}$ Health Service Executive, Cork, Republic of Ireland

${ }^{21}$ CNR Institute of Clinical Physiology, Pisa, Italy

${ }^{22}$ Registre des Malformations Congenitales de la Reunion, Saint-Pierre, Reunion

${ }^{23}$ Malformation Monitoring Centre Saxony-Anhalt, Medical Faculty Otto-von-Guericke University Magdeburg, Magdeburg, Germany

${ }^{24}$ Public Health Wales, Swansea, UK

${ }^{25}$ Institut de Pathologie at de Genetique, Charleroi, Belgium

${ }^{26}$ University of Southampton and Wessex Clinical Genetics Service, Southampton, UK

${ }^{27}$ Birth Registry Mainz Model, University Medical Centre of Johannes Gutenberg University, Mainz, Germany

Contributors: JKM, JR, and EG conceived the study. JKM did the statistical analysis and wrote the first draft of the article. EG wrote the questionnaire and distributed it. JR, EG, ML, and HD made substantial contributions to interpretation of results and revision of the manuscript. All other authors were registry representatives from EUROCAT participating registries. They contributed and validated their data and participated in the interpretation of results and critical revision of manuscript. JKM is guarantor.

Funding: This study was funded by the European Union in the framework of the Health Programme (2008-13). The funders had no role in the study design; in the collection, analysis, and interpretation of data; in the writing of the report; and in the decision to submit the article for publication. Researchers were independent of the funders.

Competing interests: All authors have completed the ICMJE uniform disclosure form at www.icmje.org/coi_disclosure.pdf and declare: no support from any organisation for the submitted work; no financial relationships with any organisations that might have an interest in the submitted work in the previous three years; no other relationships or activities that could appear to have influenced the submitted work. All authors had full access to all of the data in the study and can take responsibility for the integrity of the data and the accuracy of the data analysis.

Ethical approval: Local procedures regarding ethics approval for the registries' activities and their collaborations with EUROCAT are available on the EUROCAT website (www.eurocat-network.eu/ ABOUTUS/Member-Registries/MembersAndRegistryDescriptions/ AllMembers).

Data sharing: The data used in this study belong to the individual registries. Requests for case data can be made to the JRC-EUROCAT Central Registry (JRC-EUROCAT@ec.europa.eu), which will ask the individual registries permission to use the data. Aggregate data, updated biannually, are available from the EUROCAT website www. eurocat-network.eu/accessprevalencedata/prevalencetables. Data included in the paper were extracted from the EUROCAT database in April 2014.

Transparency: The lead author affirms that the manuscript is an honest, accurate, and transparent account of the study being reported; that no important aspects of the study have been omitted; and that any discrepancies from the study as planned have been explained.

This is an Open Access article distributed in accordance with the Creative Commons Attribution Non Commercial (CC BY-NC 3.0) license, which permits others to distribute, remix, adapt, build upon this work 
non-commercially, and license their derivative works on different terms, provided the original work is properly cited and the use is non-commercial. See: http://creativecommons.org/licenses/by-nc/3.0/.

1 Dolk $H$. The predictive value of microcephaly during the first year of life for mental retardation at seven years. Dev Med Child Neurol 1991;33:974-83. doi:10.1111/j.1469-8749.1991.tb14813.x.

2 von der Hagen M, Pivarcsi M, Liebe J, et al. Diagnostic approach to microcephaly in childhood: a two-center study and review of the literature. Dev Med Child Neurol 2014;56:732-41. doi:10.1111/ dmcn.12425.

3 Schuler-Faccini L, Ribeiro EM, Feitosa IM, et al. Brazilian Medical Genetics Society-Zika Embryopathy Task Force. Possible association between Zika virus infection and microcephaly - Brazil, 2015. MMWR Morb Mortal Wkly Rep 2016;65:59-62. doi:10.15585/mmwr. mm6503e2.

4 Rasmussen SA, Jamieson DJ, Honein MA, Petersen LR. Zika virus and birth defects--reviewing the evidence for causality. N Engl I Med 2016;374:1981-7. doi:10.1056/NEJMsr1604338.

5 Mysorekar IU, Diamond MS. Modeling Zika Virus Infection in Pregnancy. N Engl J Med 2016;375:481-4. doi:10.1056/ NEJMcibr1605445.

6 Boyd PA, Haeusler M, Barisic I, Loane M, Garne E, Dolk H. Paper 1: The EUROCAT network: organization and processes. Birth Defects Res A Clin Mol Teratol 2011;91(Suppl 1):S2-15. doi:10.1002/bdra.20780.

7 Guide EUROCAT.1.4 http://www.eurocat-network.eu/aboutus/ datacollection/guidelinesforregistration/guide1_4.

8 Loane M, Dolk H, Garne E, Greenlees R. EUROCAT Working Group. Paper 3: EUROCAT data quality indicators for population-based registries of congenital anomalies[Part A]. Birth Defects Res A Clin Mol Teratol 2011;91(Suppl 1):S23-30. doi:10.1002/bdra.20779.

9 EUROCAT. EUROCAT Statistical Monitoring Protocol 2012. 2014. http://www.eurocat-network.eu/content/Stat-Mon-Protocol(April-2014)-2012.pdf

10 EUROCAT. EUROCAT Statistical Monitoring Report - 2012. 2015 http://www.eurocat-network.eu/content/Stat-Mon-Report-2012.pdf

11 Springett A, Wellesley D, Greenlees R, et al. Congenital anomalies associated with trisomy 18 or trisomy 13 : A registry-based study in 16 European countries, 2000-2011. Am J Med GenetA 2015;167A:3062 9. doi:10.1002/ajmg.a.37355.
12 World Health Organization. WHO Child Growth Standards.http://www. who.int/childgrowth/en/. 2007.

13 Lopez-Camelo JS, Orioli IM. ECLAMC Final Document.2015. http:// www.nature.com/polopoly_fs/7.33594!/file/NS-724-2015_ECLAMCZIKA\%20VIRUS_V-FINAL_012516.pdf

14 Bhide P, Kar A. Birth prevalence of microcephaly in India. Bull World Health Organ 2016:23. doi:10.2471/BLT.16.172080.

15 National Birth Defects Prevention Network. Major birth defects data from population-based birth defects surveillance programs in the United States, 2006-2010. Birth Defects Res A Clin Mol Teratol 2013;97:S1-172

16 Teljeur C, Kelly A, Loane M, Densem J, Dolk H. Using scan statistics for congenital anomalies surveillance: the EUROCAT methodology. Eur J Epidemiol 2015;30:1165-73. doi:10.1007/s10654-015-0044-3.

17 Kleber de Oliveira W, Cortez-Escalante J, De Oliveira WT, et al. Increase in Reported Prevalence of Microcephaly in Infants Born to Women Living in Areas with Confirmed Zika Virus Transmission During the First Trimester of Pregnancy - Brazil, 2015. MMWR Morb Mortal Wkly Rep 2016;65:242-7.http://www.cdc.gov/mmwr/volumes/65/wr/ mm6509e2.htmdoi:1015585/mmwr.mm6509e2.

18 Assessment of infants with microcephaly in the context of Zika virus Interim guidance 4 March 2016 "WHO/ZIKV/MOC/16.3 Rev.1" http:// www.who.int/csr/resources/publications/zika/assessment-infants/en/.

19 Villar J, Cheikh Ismail L, Victora CG, et al. International Fetal and Newborn Growth Consortium for the 21st Century (INTERGROWTH21st). International standards for newborn weight, length, and head circumference by gestational age and sex: the Newborn CrossSectional Study of the INTERGROWTH-21st Project. Lancet 2014:384:857-68. doi:10.1016/S0140-6736(14)60932-6.

20 Júlíusson PB, Roelants M, Hoppenbrouwers K, Hauspie R, Bjerknes R. Growth of Belgian and Norwegian children compared to the WHO growth standards: prevalence below -2 and above +2 SD and the effect of breastfeeding. Arch Dis Child 2011;96:916-21. doi:10.1136/ adc.2009.166157.

21 Wright C, Lakshman R, Emmett P, Ong KK. Implications of adopting the WHO 2006 Child Growth Standard in the UK: two prospective cohort studies. Arch Dis Child 2008;93:566-9. doi:10.1136/adc.2007.126854 